\title{
Adoção de estratégias de aprendizagem por ingressantes de Ciências Contábeis de uma IES Pública de Minas Gerais
}

\author{
Moara Santiago Hirt \\ https://orcid.org/0000-0001-6138-8166 \\ Edvalda Araújo Leal \\ https://orcid.org/0000-0002-7497-5949 \\ Taís Duarte Silva \\ https://orcid.org/0000-0002-5972-8851 \\ Isolfi Vieira Rocha Neto \\ https://orcid.org/0000-0002-1522-8062
}

\section{Resumo}

Objetivo: Identificar quais estratégias de aprendizagem são utilizadas pelos ingressantes universitários do curso de Ciências Contábeis e qual a percepção deles quanto ao seu uso. As estratégias podem ser classificadas em cognitivas, metacognitivas e ausências de estratégias.

Método: A coleta de dados foi realizada durante oficinas de estratégias de aprendizagem oferecidas aos ingressantes do curso de Ciências Contábeis de uma Instituição de Ensino Superior (IES) pública. Foram aplicados questionários com base na proposta de Boruchovitch et al. (2006) e realizados grupos focais. O estudo foi composto por 132 estudantes que responderam ao questionário, desses 26 também participaram dos grupos focais.

Resultados: De modo geral, percebeu-se o predomínio da adoção de estratégias de aprendizagem metacognitivas, o que indica que os alunos têm consciência que o ato de estudar está relacionado com $o$ bom desempenho e que distrações durante os estudos podem impactar a aprendizagem. Por fim, notouse também que, o professor exerce alguma influência no desenvolvimento acadêmico, já que os discentes acreditam que o professor possui mais experiência e pode auxiliá-los no processo de aprendizagem.

Contribuições: $\mathrm{O}$ estudo traz contribuições ao evidenciar a percepção dos discentes que estão ingressando no ensino superior quanto ao processo de ensino-aprendizagem e denota a importância do uso de estratégias, a qual pode ser incentivada pelos docentes.

Palavras-chave: Estratégias de aprendizagem; Processo ensino-aprendizagem; Ingressantes. 


\section{Introdução}

O ingresso no ensino superior é almejado por diversas pessoas, que buscam oportunidades quando decidem realizar um curso. Contudo, a transição para a vida universitária é marcada também por algumas dificuldades, por exemplo, relacionadas à adaptação institucional, aos relacionamentos, aos recursos econômicos, questões vocacionais e até ao processo de aprendizagem (Casanova, Araújo \& Almeida, 2020).

Ao considerar, especificamente, as dificuldades relacionadas à aprendizagem, vale ressaltar o papel do estudante. Nesse sentido, destaca-se a importância da autorregulação, a qual evidencia o controle que o discente pode ter em seu processo cognitivo, comportamentos, motivações, bem como no uso de estratégias para alcance de determinados objetivos educacionais (Panadero \& Alonso-Tapia, 2014).

Souza (2010) demonstra que estratégias de aprendizagem consistem em métodos utilizados por discentes para aprender novos conteúdos, desenvolver habilidades que contribuirão para realização de tarefas em diversas áreas de aprendizagem. Por sua vez, Oliveira, Boruchovitch e Santos (2009) apontam que a partir do uso de estratégias de aprendizagem, os discentes podem potencializar seu próprio aprendizado.

A adoção de estratégias, por parte dos discentes, de forma autorregulada, auxilia para que eles tenham mais compromisso no próprio aprendizado (Weinstein, Acee \& Jung 2011). A respeito disso, destaca-se também o papel do docente, de disseminar e incentivar o uso dessas estratégias de aprendizagem, ou seja, auxiliar os discentes para que possam adotá-las em seus estudos, de forma a ter melhores resultados acadêmicos (Souza, 2010).

A respeito do uso de estratégias de aprendizagem no ensino superior, nota-se que os discentes tendem a usá-las de diferentes formas (García-Perez, Fraile \& Panadero, 2020). Na área de Ciências Contábeis, evidências apontam que esse uso varia, por exemplo, conforme características dos discentes (Lima Filho, Lima \& Bruni; 2015) ou a depender de questões motivacionais (Castro, Miranda \& Leal, 2016; Daciê \& Anzilago, 2019). Há também achados (Ballantine, Duff \& Larres, 2008; Hall, Ramsay \& Raven, 2004; Silva \& Biavatti, 2018) apontando que a diversidade de metodologias de ensino pode aumentar o uso de estratégias, sugerindo a influência do professor no processo de ensino.

Com base no que foi exposto, estabeleceu-se o seguinte problema de pesquisa: Quais estratégias de aprendizagem são utilizadas pelos ingressantes e como eles percebem o uso dessas estratégias em seus estudos? Assim, o objetivo deste estudo é identificar quais estratégias de aprendizagem são utilizadas pelos ingressantes universitários do curso de Ciências Contábeis e qual a percepção deles quanto ao seu uso. Como objetivo secundário, buscou-se verificar, na percepção dos alunos, a influência do professor na escolha dessas estratégias de aprendizagem.

O presente estudo busca corroborar a literatura anterior e se justifica por avaliar as quais estratégias de aprendizagem os ingressantes universitários do curso de Ciências Contábeis utilizam no processo de aprendizagem, haja vista que a graduação demanda um pensar e uma visão crítica do conteúdo, necessitando que o discente seja o protagonista do seu aprender, como demonstram Waterkemper e Prado (2011).

Acredita-se também que a utilização de estratégias de aprendizagem pode estar diretamente ligada ao sucesso acadêmico dos discentes, como demonstram Oliveira et al. (2009) e Warr e Downing (2000). Nessa perspectiva, Weinstein et al. (2011) defendem que o uso de estratégias pode contribuir para o melhor aproveitamento dos estudos no ensino superior, a partir da maior autonomia dos discentes.

Este estudo pretende trazer contribuições ao identificar as estratégias de aprendizagem adotadas por ingressantes no curso de Ciências Contábeis, e é também um modo de verificar quais os possíveis métodos e preferências no estudo contábil, bem como identificar a visão dos discentes quanto ao papel do docente no uso dessas estratégias. Além disso, outra contribuição deste estudo é o método de coleta de dados, o qual se deu por meio de oficinas de estratégias ofertadas aos ingressantes. 


\section{Referencial Teórico}

O referencial teórico aborda as estratégias de aprendizagem, evidenciando a importância de sua utilização e como seu uso pode influenciar na aprendizagem. Além disso, apresentam-se estudos correlatos sobre as estratégias de aprendizagem utilizadas por discentes do ensino superior, principalmente do curso de Ciências Contábeis, bem como a influência docente no momento em que os alunos determinam suas estratégias.

\subsection{Estratégias de Aprendizagem no Processo de Ensino}

Entre os anos de 1970 e 80, estudos seminais de John H. Flavell (1979), sobre a metacognição, e de Merlin C. Wittrock, sobre o processamento cognitivo ativo, forneceram evidências de que essas estratégias de aprendizagem são aliadas do processo de aprender (Weinstein et al., 2011). Desde então, iniciaram-se as pesquisas sobre a temática, nas quais os autores buscam definir teoricamente o que são as estratégias de aprendizagem.

Na perspectiva de Mayer (1988), as estratégias de aprendizagem são comportamentos que influenciam no processamento de informações; para Dembo (1994), são processos e métodos utilizados por estudantes, com o intuito de facilitar a aquisição, a utilização e o armazenamento de informações. Em linha, Valle Arias, Lozano e Cabanach (1999) as definem como sendo ações conscientes do aprendiz, o qual, na execução de uma tarefa, lançam mão de procedimentos, táticas e técnicas orientadas à consecução dos seus objetivos de aprendizagem. Boruchovitch (1999) relata que as estratégias de aprendizagem consistem em um processo fundamental da capacidade e do processo de aprender dos discentes, além de tentar prevenir as dificuldades de aprendizagem. Para Oliveira et al. (2009) e Warr e Downing (2000), elas potencializam a aprendizagem dos alunos, desenvolvem o controle da própria aprendizagem e melhoram a capacidade de recuperação de informações já aprendidas.

Em síntese ao que foi exposto no parágrafo anterior, considera-se na presente pesquisa que as estratégias de aprendizagem podem ser entendidas como comportamentos que influenciam o processamento do conteúdo, de forma que diferentes objetivos de aprendizagem demandam o uso de diferentes estratégias.

Ao discutir sobre aprendizagem, cabe ressaltar a importância da aprendizagem autorregulada, a qual parte do pressuposto que os discentes têm capacidade para estabelecer planos e estratégias que possibilitem alcançar um objetivo de aprendizagem (Freire, 2009). A autorregulação da aprendizagem indica mais autonomia e mais proatividade dos discentes no processo de aprender (Simão \& Frison, 2013).

A autorregulação auxilia os discentes na gestão do aprendizado de forma estratégica, estando entre os três principais elementos no escopo das estratégias de aprendizagem, com destaque também para a habilidade, que está relacionada ao conhecimento de como usar as estratégias; e a vontade, que indica a motivação e elementos afetivos das estratégias (Weinstein et al., 2011). A partir desse entendimento, é possível verificar a importância do uso das estratégias autorreguladas na busca pelo sucesso acadêmico (Weinstein et al., 2011).

As estratégias no processo de aprendizagem abrangem as ações que possibilitam que um indivíduo consiga ter mais eficácia na realização de uma atividade (Ribeiro, 2003), contribuindo com o processamento de informações durante os estudos (Oliveira et al., 2009). Em pesquisas anteriores (Boruchovitch, 1999; Boruchovitch, 2006; Boruchovitch \& Santos, 2015; Oliveira et al., 2009; Ribeiro, 2003; Souza, 2010), as estratégias de aprendizagem são classificadas, de forma ampla, em dois grandes grupos: metacognitivas e cognitivas. 
As estratégias de aprendizagem metacognitivas dizem respeito às técnicas de planejamento, monitoramento e regulação usados antes, durante a após ao processo aprendizagem (Valle Arias et al., 1999). A ideia da metacognição concebida por Flavell (1979) consiste em reconhecer o próprio conhecer com o intuito de aprender, destacando a importância do aprender a aprender nesse processo (Ribeiro, 2003). E ainda que se tenha diferentes conceitos relativos à metacognição, destaca-se como aspecto em comum mecanismos que auxiliam na promoção, produção e gravação de informações, além de monitorar o próprio processamento intelectual (Lima Filho et al, 2015).

A metacognição auxilia na melhoria da cognição, da motivação e do aprendizado (Ribeiro, 2003), assim é requerida constantemente no âmbito acadêmico e deve ser objeto de intervenção com a finalidade de prevenir dificuldades no aprendizado (Corso, Sperb, Jou \& Salles, 2013). Nesse sentido, as estratégias metacognitivas são aquelas relacionadas à ação de monitorar e autocontrolar o processo de aprender, as quais evidenciam a capacidade do discente de refletir sobre esse processo (Boruchovitch, 1994). Assim, com o uso de estratégias metacognitivas, o discente pode potencializar seu aprendizado (Oliveira et al., 2009).

As estratégias cognitivas são as técnicas usadas pelos alunos para efetivar o processo de aprendizagem (Valle Arias et al., 1999), e estão diretamente relacionadas com o os objetivos de aprendizagem dos alunos (Boruchovitch, 1994; Ribeiro, 2003). Essas estratégias cognitivas podem ser utilizadas após as metacognitivas, quando, diante de uma situação, o estudante percebe qual trajeto percorrer para aprender o conteúdo (Ribeiro, 2003).

Ao comparar os dois grupos de estratégias de aprendizagem, observa-se que as metacognitivas são mais amplas (Souza, 2010) e referem-se ao processo de conscientização diante de casos em que a aprendizagem pretendida não está sendo alcançada, assim composta por planejamento, monitoramento e regulação dos processos cognitivos, afetivos e motivacionais (Boruchovitch et al., 2006).

Já as cognitivas são mais específicas, associadas à execução de tarefas (Souza, 2010). Conforme aponta Abdullah et al. (2015), dentro desse grupo tem-se três ramificações, são elas: o ensaio, que consiste na repetição de informações aprendidas; a elaboração, que se refere à associação de informações com informações já adquiridas; e a organização, que é a estruturação do conhecimento a ser aprendido.

Considerando as diferenças entre os dois grupos de estratégias, apresentam-se, na Tabela 1, as definições e os procedimentos adotados em cada grupo. 
Tabela 1

Estratégias de Aprendizagem

\begin{tabular}{|c|c|c|}
\hline Estratégias & Definições & Procedimentos \\
\hline \multicolumn{3}{|c|}{ Estratégias de aprendizagem Metacognitivas } \\
\hline Planejamento & Definição de metas para o estudo. & $\begin{array}{l}\text { Adequar as estratégias aos objetivos de } \\
\text { aprendizagem. }\end{array}$ \\
\hline Monitoramento & $\begin{array}{l}\text { Autoconhecimento das capacidades e } \\
\text { limitações cognitivas. }\end{array}$ & $\begin{array}{l}\text { Monitorar a motivação e a ansiedade, planejar } \\
\text { as tarefas, controlar o esforço, monitorar } \\
\text { e regular a compreensão do conteúdo, } \\
\text { identificar e corrigir os erros, controlar o } \\
\text { tempo, organizar o ambiente de estudo. }\end{array}$ \\
\hline Regulação & $\begin{array}{l}\text { Conhecimento sobre as estratégias de } \\
\text { aprendizagem, como usá-las e sob que } \\
\text { circunstâncias. }\end{array}$ & $\begin{array}{l}\text { Conhecer várias estratégias e mudá-las, caso } \\
\text { os objetivos de aprendizagem não estejam } \\
\text { sendo alcançados. }\end{array}$ \\
\hline \multicolumn{3}{|c|}{ Estratégias de aprendizagem Cognitivas } \\
\hline Ensaio & $\begin{array}{l}\text { Repetição ativa daquilo que está sendo } \\
\text { aprendido. }\end{array}$ & $\begin{array}{l}\text { Tomar notas, ouvir gravações ou podcasts } \\
\text { sobre o conteúdo e grifar/destacar o material. }\end{array}$ \\
\hline Elaboração & $\begin{array}{l}\text { Tratamento e transformação do material para } \\
\text { que ele se torne significativo. }\end{array}$ & $\begin{array}{l}\text { Parafrasear, resumir, explicar a outra } \\
\text { pessoa, criar perguntas e respostas, fazer } \\
\text { comparações. }\end{array}$ \\
\hline Organização & $\begin{array}{l}\text { Esquematização do material de forma a } \\
\text { diferenciá-lo ou reorganizá-lo a fim de torná-lo } \\
\text { significativo. }\end{array}$ & $\begin{array}{l}\text { Elaborar mapas conceituais, esquemas, } \\
\text { enumerações, diagramas. }\end{array}$ \\
\hline
\end{tabular}

Fonte: elaborado pelos autores com base em Abdullah et al. (2015), Boruchovitch e Santos (2015) e Weinstein et al. (2011).

Após analisar a Tabela 1, é importante levar em consideração que os meios e métodos de aprendizagem dos discentes não são únicos, assim, cada discente utiliza e busca o que considera ser melhor e mais adequado, nem sempre havendo uma unanimidade de considerações sobre as estratégias de aprendizagem. Conforme Borges (2016) e Weinstein et al. (2011), alguns procedimentos podem ser úteis para determinado perfil de aluno, ao passo que para outro não o é. Por esse motivo, os alunos devem ser capacitados a avaliar quais estratégias são mais adequadas aos seus objetivos de aprendizagem (Boruchovitch, 2006).

As estratégias adotadas para aprender são sensíveis ao ambiente educacional em que os alunos estão inseridos (Hall et al., 2004), de modo que, diferentes tipos de conteúdo e atividades, podem demandar que novas estratégias sejam assumidas, e/ou que as antigas sejam reformuladas. Nesse sentido, Souza (2010) assevera que é necessário levar em conta o ambiente de sala de aula e que os discentes sejam encorajados pelos docentes para a adoção de novas estratégias de aprendizagem.

$\mathrm{O}$ uso e a descoberta de novas estratégias de aprendizagem podem ser incentivados pelos professores, seja pela evidenciação de técnicas de estudo, bem como pela aplicação de atividades que estimulem os alunos a refletirem sobre seu aprendizado (Ballantine et al., 2008; Boruchovitch, 1999). Além disso, a combinação de estratégias, ou seja, utilizar mais de um tipo durante o aprendizado também é benéfico e contribui para o alcance de bons resultados (Glogger, Schwonke, Holzapfel, Nuckles \& Renkl, 2012).

Em contrapartida ao que foi discutido anteriormente, menciona-se também a ausência de estratégias no processo de aprendizagem. Segundo Boruchovitch et al. (2006), a ausência de estratégias de aprendizagem se dá devido a comportamentos negativos que irão influenciar o uso estratégias de aprendizagem, ou mesmo levar ao não uso de estratégias e à falta de regulação. Castro et al. (2016) indicam que, quanto mais a pressão externa aumenta sobre o discente, em questões de aprendizagem, menos as estratégias são utilizadas.

Entende-se que os motivos de não utilizar estratégias ou terem comportamentos desfavoráveis no estudo são diversos. Contudo, destaca-se na presente pesquisa um fator que pode prejudicar os discentes, que é o uso de celulares em sala de aula, conforme discutido por Mateus \& Brito (2011) e Araújo, Santos \& Alves (2019). Esses autores citam que os celulares, geralmente, propiciam distrações e que o uso inadequado desses aparelhos pode trazer danos ao estudo dos discentes. 
Após a apresentação dos principais conceitos relativos às estratégias de aprendizagem, evidenciamse, na sequência, estudos correlatos realizados com alunos de diferentes áreas (García-Perez et al., 2020; Monteiro, Vasconcelos \& Almeida, 2005) e, exclusivamente, com estudantes da área contábil (Ballantine et al., 2008; Castro et al., 2016; Daciê \& Anzilago, 2019; Hall et al., 2004; Lima Filho et al., 2015; Morozini, Cambruzzi \& Longo, 2007; Silva \& Biavatti; 2018; Vasconcelos \& Araújo; 2017), que abordam o processo de ensino-aprendizagem, bem como as estratégias de aprendizagem.

Monteiro et al. (2005) analisaram métodos de estudos de 242 discentes de primeiro ano de cursos de engenharia. Dos resultados, destacou-se que o enfoque compreensivo, aquele em que o discente reflete de forma mais profunda o conteúdo e a percepção de ter maiores competências, associou-se com maiores resultados no rendimento acadêmico. Diante disso, o autor enfatizou a importância do professor, para que possa incentivar o discente a ter comportamentos reflexivos e papel ativo em seu aprendizado.

García-Perez et al. (2020) realizaram um estudo com universitários de psicologia e ciências do esporte, para investigar suas decisões referentes ao uso de estratégias de aprendizagem. A partir de uma abordagem qualitativa, os autores identificaram que os discentes adotavam estratégias, principalmente no período das avaliações; alguns usavam sempre as mesmas estratégias, outros mudavam, a depender do conteúdo estudado, ou até do formato da avaliação e perceberam que discentes com menor rendimento relataram mais dificuldades quanto ao uso de estratégias.

$\mathrm{Na}$ área contábil, Morozini et al. (2007) objetivaram identificar fatores que influenciam e dificultam o processo de ensino-aprendizagem na percepção de 209 discentes. Os autores identificaram que a metodologia de ensino adotada pelo docente pode facilitar a aprendizagem do discente, e a depender também dessa metodologia o discente pode sentir-se mais motivado. Nesse sentido, destacaram a importância da participação do discentes no próprio aprendizado.

Com propósito de analisar estratégias de aprendizagem autorreguladas, considerando algumas características dos discentes, Lima Filho et al. (2015) pesquisaram 249 graduandos de contabilidade e verificaram que respondentes do sexo feminino e mais jovens apresentavam níveis mais elevados de aprendizagem autorregulada. A partir desses resultados, os autores ressaltaram a importância das estratégias no ensino, e ponderaram sobre a necessidade de maior atenção aos discentes com menor autorregulação.

Castro et al. (2016) buscaram analisar a relação entre estratégias de aprendizagem e motivação para aprender, a partir de uma amostra de 480 graduandos em Ciências Contábeis de uma universidade pública brasileira. Os autores identificaram associação positiva entre a motivação intrínseca e uso de estratégias, bem como entre a motivação extrínseca e ausência de estratégias, evidenciando que a forma como os discentes conduzem seu aprendizado tem relação com a motivação que eles apresentam. Em estudo similar, Daciê e Anzilago (2019) investigaram 106 discentes do mesmo curso, porém de outra instituição, e notaram relação positiva entre a motivação intrínseca e estratégias de estudo aprofundadas.

Em análise específica de um procedimento adotado nas estratégias cognitivas, Vasconcelos e Araújo (2017) investigaram benefícios oriundos do uso de mapas conceituais no ensino-aprendizagem. A partir de um estudo qualitativo, analisaram a utilização de mapas em duas disciplinas da área contábil, com 48 discentes. Dos resultados encontrados, destaca-se que os mapas contribuem para o desenvolvimento de habilidades sociais e de comunicação, para estabelecer conexões interdisciplinares, bem como para favorecer a autonomia dos discentes.

Hall et al. (2004) redesenharam a estrutura de uma disciplina introdutória de contabilidade por meio da inserção de uma série de metodologias de ensino inovadoras, a fim de avaliar mudanças no uso de estratégias de aprendizagem pelos alunos, as quais foram levantadas por meio do inventário SPQ (superficial e profunda). Observou-se que, ao final da intervenção, os alunos haviam não apenas intensificado o uso de estratégias de aprendizagem mais profundas (ler, procurar conexões e integrar novos conceitos com o conhecimento anterior), como também haviam diminuído o uso de outras mais superficiais. 
Em linha com o estudo citado acima, Ballantine et al. (2008) realizaram uma pesquisa longitudinal durante um ano letivo com alunos de cursos de contabilidade e de negócios de uma universidade irlandesa com a finalidade de analisar o efeito do método do caso no uso das estratégias de aprendizagem. Os autores utilizaram o inventário ASSIST, que identifica três abordagens de aprendizagem: profunda, superficial e estratégica. Os achados apontaram que a aplicação da metodologia ativa incentivou os alunos a buscarem ou reforçarem estratégias de aprendizagem tanto profundas (relacionar conceitos novos com conhecimentos prévios) quanto estratégicas (organizar o estudo e gerenciar o tempo disponível).

Por fim, apresenta-se o estudo de Silva e Biavatti (2018), no qual analisaram a relação entre o perfil autorregulado de aprendizagem dos discentes aos métodos educacionais de ensino e a percepção docente sobre a aprendizagem. Investigaram 202 discentes e 16 professores de um curso de Ciências Contábeis. Verificaram que os discentes usam estratégias metacognitivas e esse uso aumenta à medida que os discentes avançam no curso; os docentes mostraram ter entendimento sobre quais métodos contribuem para a aprendizagem e habilidades metacognitivas dos discentes, ainda que esses não sejam os métodos mais adotados. Observaram ainda que a diversidade de métodos de ensino pode ter contribuído para o maior uso de estratégias.

\section{Metodologia}

\subsection{Classificação da Pesquisa}

Como objetivo principal, este estudo visa identificar quais estratégias de aprendizagem são utilizadas pelos ingressantes universitários do curso de Ciências Contábeis e qual a percepção deles quanto a esse uso. Como objetivo secundário, buscou-se verificar, na percepção dos alunos, a influência do professor na escolha dessas estratégias de aprendizagem. O estudo classifica-se como descritivo e com a abordagem predominantemente qualitativa dos dados. Conforme Cervo e Bervian (1996, p. 66), "a pesquisa descritiva observa, analisa e correlaciona fatos ou fenômenos (variáveis) sem manipulá-los”. Esses autores afirmam ainda que a pesquisa descritiva "procura descobrir, com a previsão possível, a frequência com que um fenômeno ocorre, sua relação e conexão com outros, sua natureza e características".

O público-alvo do estudo são ingressantes no curso de Ciências Contábeis de uma Instituição de Ensino Superior pública localizada em Minas Gerais. A população desta pesquisa é composta por, aproximadamente, 160 discentes matriculados nos turnos integral e noturno no $1^{\circ}$ e no $2^{\circ}$ semestre letivo do ano de 2019. Ressalta-se que a forma de ingresso nesta IES se dá semestralmente por processo seletivo próprio e/ou pelo Exame Nacional do Ensino Médio (Enem), são ofertadas 80 vagas por semestre para os turnos integral e noturno

A IES selecionada para este estudo tem uma faculdade de Ciências Contábeis que conta com um grupo de docentes atuantes no ensino, pesquisa e extensão, especificamente, no Programa de Educação Tutorial (PET), no Master of Business Administration (MBA), na Empresa Júnior (Contábile) e nos cursos de pós-graduação stricto sensu (mestrado e doutorado). Nessa instituição, os autores deste trabalho, em conjunto com o PET da faculdade em estudo, ofertaram oficinas destinadas a orientar os novos alunos quanto ao uso de estratégias no processo de aprendizagem. Além das características mencionadas, ressalta-se que a escolha pelo público, de ingressantes, se deu também em virtude de o ensino superior ser o início de um novo ciclo educacional que exige que eles lancem mão de estratégias de aprendizagem que os coloquem como protagonistas do seu aprendizado (Waterkemper \& Prado, 2011). 


\subsection{Procedimentos de Coleta dos Dados}

A coleta de dados foi realizada durante as oficinas denominadas "Como os estudantes aprendem? Estratégias de Aprendizagem no Processo Ensino Aprendizagem" oferecidas aos estudantes ingressantes no curso de Ciências Contábeis no $1^{\circ}$ e no $2^{\circ}$ semestre de 2019. Essas oficinas são ofertadas pelo PET da instituição em estudo, sendo os ministrantes os professores do curso e alunos do programa de pósgraduação em Ciências Contábeis.

O objetivo das oficinas é apresentar aos ingressantes as principais estratégias de aprendizagem que podem ser adotadas por eles com o propósito de obter melhor desempenho no processo de aprendizagem. Assim, são realizadas atividades práticas com a aplicação de estratégias de aprendizagem, das quais os estudantes participam ativamente. Vale destacar que, antes do início da oficina, os discentes foram informados sobre a realização dessa pesquisa pela professora responsável, que também explicou o objetivo e apresentou as informações necessárias, do termo de consentimento livre e esclarecido, para que os discentes pudessem decidir se aceitariam ou não participar da pesquisa.

Nessas oficinas, após a apresentação das principais estratégias de aprendizagem, realizou-se a coleta dos dados utilizados no presente estudo. Para alcançar o objetivo deste estudo de identificar se ingressantes universitários do curso de Ciências Contábeis adotam estratégias de aprendizagem, na primeira etapa da coleta aplicou-se um questionário para identificar quais são as estratégias de aprendizagem utilizadas pelos estudantes. Esse questionário é constituído por dois blocos, o primeiro visa à caracterização dos respondentes, levantando informações demográficas, como: sexo, idade, turno e experiência profissional e o segundo busca conhecer o comportamento dos discentes quanto ao uso das estratégias de aprendizagem, utilizando o instrumento de Boruchovitch et al. (2006).

O instrumento estruturado de Boruchovitch et al. (2006) é composto de 20 assertivas, dessas, 6 abordam as estratégias cognitivas, 6 as estratégias metacognitivas e 8 denotam a ausência de estratégias de aprendizagem. Foi solicitado aos discentes que atribuíssem uma nota de 0 (Nunca) a 10 (Sempre) (podendo utilizar valores decimais) a cada assertiva, considerando a intensidade de concordância ou não com tais afirmativas. Assim, a soma total para cada um dos construtos será de, no máximo, 60, 60 e 80 pontos, para estratégias cognitivas, metacognitivas e ausência de estratégias, respectivamente. Ressalta-se que todos os alunos presentes na oficina participaram respondendo aos instrumentos de coleta de dados utilizados neste estudo.

Para complementar a compreensão dos resultados obtidos por meios dos questionários, na segunda etapa da coleta de dados, solicitou-se aos participantes um relato, por escrito, sobre as estratégias que eles adotam no processo de ensino e que consideram que os ajudam a enfrentar seus principais obstáculos de aprendizagem.

Com o propósito de verificar, na percepção dos alunos, a influência do professor na escolha dessas estratégias, foram solicitados relatos dos alunos sobre como os professores podem auxiliar na adoção das estratégias de aprendizagem no ambiente escolar, tendo sido declarada a preservação da identidade dos respondentes ao solicitar o uso das respostas para este estudo.

Assim, com o propósito de aprofundar a compreensão sobre o tema em estudo, foram realizados grupos focais (entrevistas coletivas) com participantes voluntários ao final das oficinas. Segundo Caplan (1990), os grupos focais podem ser definidos como pequenos grupos que visam avaliar conceitos ou identificar a presença de problemas. Além disso, Vaughn, Schumm e Sinagub (1996), que utilizam essa metodologia em pesquisas na área educacional, relatam que é possível aprofundar o conhecimento de necessidades por meio dessa metodologia.

No total, foram realizados 4 grupos focais, 2 no primeiro semestre e 2 no segundo semestre de 2019 , ao todo participaram 26 alunos. Os grupos focais foram mediados pela professora ministrante da oficina com o apoio dos pós-graduandos, com o tempo médio das sessões de dezesseis minutos e dezoito segundos. Optou-se por gravar o áudio com um gravador de celular e, posteriormente, realizou-se a transcrição manual das gravações. Para preservar a identidade dos participantes, as declarações dos entrevistados foram indicadas pela letra "P" (participante) seguida por uma numeração sequencial, sendo: P1, P2, P3, ..., e P26. 


\subsection{Participantes da Pesquisa e Procedimentos de Análise dos Dados}

Para tratar os dados obtidos por meio dos questionários, foi realizada a análise descritiva das respostas, bem como foi apresentada as médias das notas indicadas pelos participantes para os grupos de estratégias de aprendizagem (cognitiva, metacognitiva e ausência de estratégias). Os participantes do estudo correspondem a 132 estudantes que se prontificaram a responder o questionário.

Com relação ao grupo focal, a primeira oficina foi realizada no primeiro semestre de 2019 e contou com a participação de 15 alunos, sendo 6 da turma A (turno integral) e 9 da turma B (turno noturno). Os participantes na análise são indicados (citados) para o primeiro semestre da turma do integral como A1P1, A1P2 e os subsequentes e, para a turma noturno, B1P1, B1P2 e os seguintes. Já na segunda oficina, realizada no segundo semestre de 2019, foram 11 os alunos participantes do grupo focal, dentre eles, 7 eram da turma integral e 4 da turma noturno, sendo classificados os da turma integral como A2P1, A2P2 e os subsequentes e da turma do turno noturno, B2P1, B2P2 e os sequenciais.

Para analisar os relatos obtidos por meio das entrevistas de grupo focal, elaborou-se, inicialmente, a Nuvem de Palavras com o intuito de identificar a frequência das palavras citadas pelos alunos. Para as nuvens de palavras, optou-se por utilizar somente as classes "adjetivos", "substantivos" e "verbos" como palavraschave ativas, o que se deu por meio do software gratuito de análise de dados qualitativos, IRAMUTEQ.

Além disso, foi utilizada a análise de conteúdo, abrangendo quatro etapas: (i) organização da análise; (ii) codificação; (iii) categorização; (iv) inferências. Segundo Bardin (1977), a análise de conteúdo, que contempla essas quatro etapas do estudo, utiliza técnicas de análise que buscam encontrar, por meios de procedimentos, o conteúdo de mensagens por meio de indicadores (que podem ser quantitativos ou não) que permitam relacionar as condições de produção/recepção dessas mensagens.

No que se refere à análise qualitativa, foram adotadas duas categorias de análise, são elas: (i) Estratégias de Aprendizagem e o Ensino;(ii) Papel do Professor na Escolha das Estratégias. Essas categorias foram utilizadas na análise do grupo focal e dos relatos escritos e tiveram como embasamento estudos anteriores, tais como os de Oliveira et al. (2009) e Souza (2010).

\section{Análise dos Resultados}

\subsection{Análise Descritiva}

Durante as oficinas, foi aplicado um questionário aos alunos com a finalidade de identificar as características dos respondentes. Com isso, foi possível identificar dados como: sexo, idade, turno e experiência profissional.

Tabela 2

\section{Caracterização dos respondentes}

\begin{tabular}{llll}
\hline Sexo & & Turno & \\
\hline Feminino & $46,97 \%$ & Integral & $52,27 \%$ \\
\hline Masculino & $53,03 \%$ & Noturno & $47,73 \%$ \\
\hline Idade & & Trabalho & \\
\hline Até 19 & $61,36 \%$ & Não trabalha & $55,30 \%$ \\
\hline De 20 a 22 & $24,24 \%$ & Sim, mas não na área & $40,91 \%$ \\
\hline De 23 a 25 & $6,82 \%$ & Não respondeu & $3,79 \%$ \\
\hline Acima de 25 & $7,58 \%$ & & \\
\hline
\end{tabular}

Fonte: dados da pesquisa. 
Conforme os dados da Tabela 2, constata-se que mais da metade $(53,03 \%)$ dos respondentes são alunos do sexo masculino, tendo a maioria $(61,36 \%)$ idade de até 19 anos e a minoria $(7,58 \%)$ com idade acima de 25 anos. O turno com mais alunos matriculados e frequentes é o integral, sendo verificado ainda que 55,30\% dos respondentes não trabalham.

Além disso, o questionário também possibilitou o reconhecimento das estratégias de aprendizagem com as quais os alunos mais se identificam e que eles utilizam. A análise dos tipos de estratégias é apresentada na Tabela 3, para tanto considerou-se os valores somatórios (total) de cada tipo, os quais poderiam variar de 0 a 60 para estratégias cognitivas e metacognitivas e 0 a 80 para ausência de estratégias.

Tabela 3

\section{Estratégias de Aprendizagem}

\begin{tabular}{lccccc}
\hline Estratégias & Média & Mediana & Moda & Mínimo & Máximo \\
\hline Cognitiva & 31,17 & 32,00 & 32,00 & 0,00 & 56,00 \\
\hline Metacognitiva & 50,11 & 50,00 & 52,00 & 33,00 & 60,00 \\
\hline Ausência & 39,71 & 40,00 & 50,00 & 4,00 & 80,00 \\
\hline
\end{tabular}

Fonte: dados da pesquisa.

Ao observar os valores indicados na Tabela 3 e considerando as devidas proporções dos valores totais de cada tipo de estratégia, nota-se que na amostra analisada houve predominância do uso de estratégias metacognitivas. Ribeiro (2003) ressalta que a metacognição consiste em reconhecer o próprio conhecer, ou seja, é verificar como se conhece e/ou aprende. Pelos dados analisados infere-se que na média, os alunos têm a percepção da importância do processo de aprendizado, ainda que nem todos utilizem as estratégias da mesma forma. Esse resultado vai ao encontro dos achados de Lima et al. (2015) que identificaram discentes de contabilidade usando mais estratégias de autoavaliação, ajuda externa e ambiente, as quais estão relacionadas à metacognição.

Referente às estratégias cognitivas, vale destacar que permitem alcançar objetivos de aprendizado (Ribeiro, 2003), direcionadas a execução de tarefas (Souza, 2010). Nota-se que os alunos usam essas estratégias, já que a média encontrada $(31,17)$ foi pouco acima da metade do valor total possível $(60)$, resultado similar foi verificado pela mediana (32). Entretanto, há alunos que não adotam qualquer estratégia cognitiva, visto que o valor mínimo encontrado foi 0,0 .

Já a ausência de estratégias se justifica devido aos comportamentos negativos que irão influenciar as estratégias de aprendizagem, como, por exemplo, o não uso de estratégias e a falta de regulação, como afirmam Boruchovitch et al. (2006). A média da não utilização de estratégias totaliza 39,71, sendo proporcionalmente a menor média encontrada se comparada aos resultados do grupo de metacognição e do grupo de cognição. Evidências anteriores (Castro et al., 2016) indicaram que pressões externas, características de motivação extrínseca podem favorecer o não uso de estratégias. Nesse sentido, destacase a relevância de que os estudantes mantenham motivação intrínseca durante o curso.

\subsection{Análise Qualitativa}

\subsubsection{Grupo Focal}

$\mathrm{Na}$ análise inicial dos relatos obtidos por meio das entrevistas de grupos focais, elaborou-se uma nuvem de palavras para verificar quais delas mais se repetiam na fala dos alunos. Conforme apontado na metodologia, foram considerados os adjetivos, os substantivos e os verbos. A nuvem é apresentada na Figura 1. 
Analisando a frequência geral, identifica-se um total de 539 palavras ativas que foram citadas 1859 vezes. De acordo com a nuvem (Figura 1), as palavras centralizadas, que se destacam pelo tamanho da fonte, são as mais utilizadas durante os grupos focais. Portanto, nota-se, nitidamente, que as palavras "professor" (39 menções), "achar" (33 menções) e "estudar" (32 menções) foram as mais frequentes nos relatos dos alunos no momento das entrevistas, representando, respectivamente, $2,1 \%, 1,78 \%$ e $1,72 \%$ da frequência geral.

Para compreender o sentido das palavras mais repetidas ("professor", "achar" e "estudar") e confirmar o contexto no qual foram empregadas, foi necessária a realização de uma subanálise. Assim, foi possível identificar que a variada utilização da palavra "professor" está associada ao fato de os alunos acreditarem que o professor, com toda a sua experiência e prática, pode ter grande influência na carreira acadêmica de seus alunos. Já o verbo "achar" foi mais usado para expor as opiniões debatidas e expostas sobre as estratégias de aprendizagem. Quanto ao emprego do verbo "estudar", constata-se que os discentes estão conscientes que o bom desempenho também depende de um bom e organizado estudo.

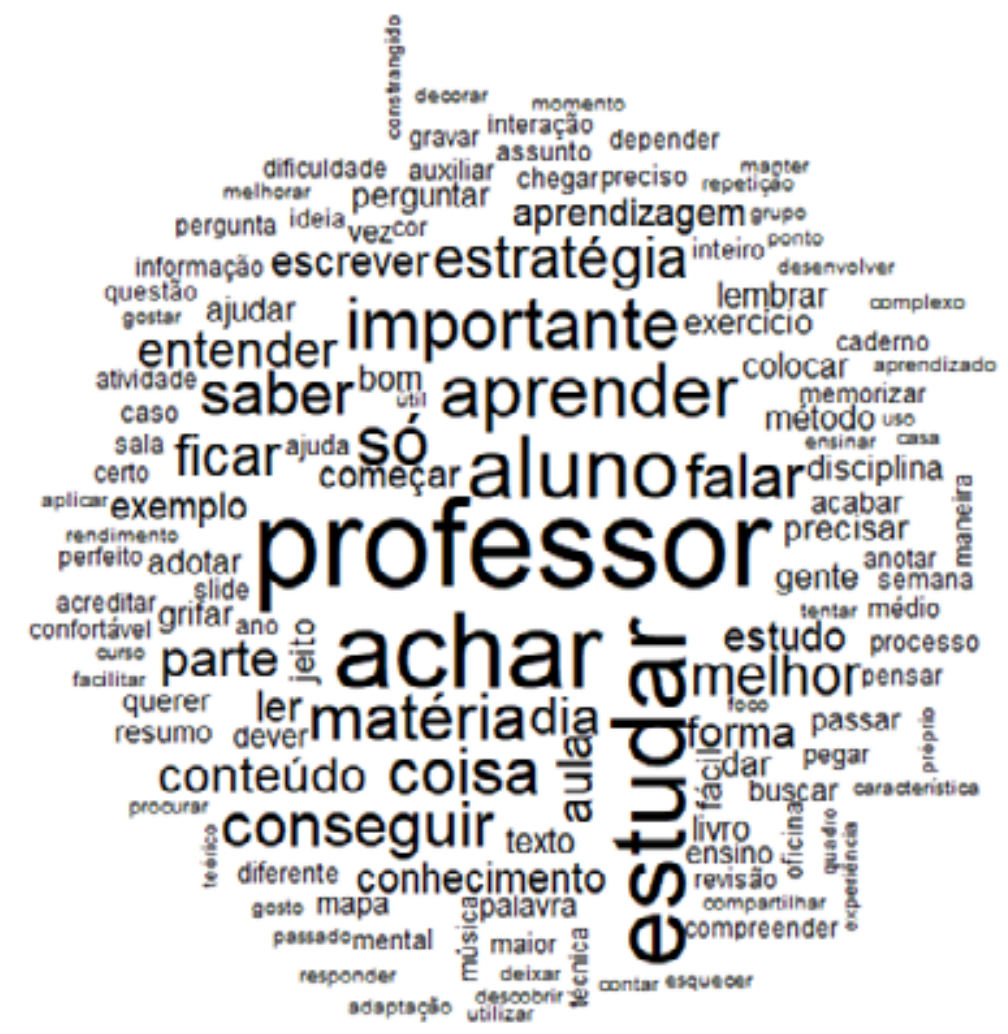

Figura 1. Nuvem de palavras das entrevistas de grupos focais

Fonte: dados da pesquisa.

Além da nuvem de palavras, apresentam-se alguns trechos que foram citados pelos alunos durante a realização do grupo focal. Inicialmente, destacam-se os trechos que se referem à categoria estratégias de aprendizagem e ensino.

Eu faço mapas mentais, mas foco mais na parte de revisão. Sempre faço mapa mental porque é a maneira mais fácil de poder frisar, é um ciclo... se eu estudar hoje, eu tenho que estudar e rever amanhã e, depois, em uma semana, depois, em sete dias de novo e, por fim, só em trinta dias. E, então, nunca mais esqueço. A revisão, acho que é o que mais mantém. Se você só vê uma vez, pode até lembrar depois de uma coisa ou outra, mas, se você ver sempre, vai ter um aproveitamento de $100 \%$ (A1P2). 
Quando a pessoa é livre, o dia inteiro, com certeza, ela vai buscar uma forma de estudo mais intensificada. A adaptação do tempo com a sua necessidade de estudo interfere nas estratégias que devemos adotar. Eu, que trabalho e que tenho que vir estudar, acabo fazendo resumos e grifo partes que acho importantes. Para mim, é muito mais fácil pelo pouco tempo que tenho disponível (B1P4).

Eu acho que o estudo individual é muito importante. Muita gente gosta de grupo e eu até entendo que é melhor compartilhar as ideias porque tem pessoa que é boa em uma coisa e tem pessoa que é boa em outra. Só que, estudando individualmente, eu consigo entender qual é a minha dificuldade, ver no que eu tenho que focar e acho isso muito importante (A2P4).

As estratégias de aprendizagem representam uma etapa fundamental para o processo de aprender dos discentes, visto que, por meio delas, as dificuldades de aprendizagem podem ser prevenidas, como afirma Boruchovitch (1999). A partir dos relatos acima, entende-se que os discentes utilizam das estratégias de aprendizagem para aperfeiçoar o conhecimento adquirido e memorizá-lo a longo prazo. Entende-se também que a adoção das estratégias resulta em um melhor aproveitamento do ensino, sendo também eficaz para a otimização do tempo que, em muitos casos, é limitado.

Ainda a respeito das estratégias, destaca-se a citação de um discente sobre o uso de mapas mentais, esse relato corrobora os achados de Vasconcelos e Araújo (2017), que perceberam a importância dos mapas no estabelecimento de conexões no aprendizado. Já no segundo relato, verifica-se que o uso de estratégias pode variar dependendo da situação do estudante, a respeito disso observou-se no estudo de García-Perez et al. (2020) que alguns aspectos podem afetar a decisão de adotar estratégias. Cabe pontuar ainda o relato indicando a importância de compreender as próprias dificuldades, entende-se que essa ação seria característica das estratégias metacognitivas, as quais segundo Oliveira et al. (2009) podem intensificar o aprendizado.

Notou-se ainda que os alunos percebem o importante papel do professor na escolha das estratégias, conforme os relatos que se seguem:

O próprio professor estudou aquela matéria. Então, no seu processo de aprendizagem, também desenvolveu técnicas que podem ser compartilhadas com os alunos, contribuindo para o aprendizado deles. [...] Por exemplo, quando vou estudar uma matéria que nunca tive contato, inicialmente, terei dificuldade de toda forma. Então, o professor pode orientar quais os aspectos são importantes para ter um rendimento melhor/ maior. Então, facilitará, utilizando a experiência dele com aquele conteúdo (A1P4).

As estratégias que o professor usa, no caso, se ele vai acompanhar um livro, se ele vai só escrever no quadro ou se vai usar um slide, isso tudo cada pessoa aprende de um jeito. Então, se ele diversificar, ele pode atingir vários alunos $(\mathrm{A} 2 \mathrm{P} 1)$.

Eu acho que, exigindo seminários, independente se é matéria teórica ou menos conceitual, a apresentação de seminário usa de todos os jeitos as técnicas porque ele não é só encher o slide de texto e, sim, colocar um tópico e explicá-lo, portanto, auxilia muito no aprendizado (A1P1).

Morozini et al. (2007) afirmam que os alunos são influenciados pelo professor, uma vez que eles estudaram intensamente e por bastante tempo o conteúdo que será ministrado em aula, ou seja, o professor tem propriedade sobre o assunto e isso gera conforto ao aluno. No caso deste estudo, é relatado que os docentes devem ministrar suas aulas de maneira menos complexa e com mais exemplos de suas experiências, diversificando suas estratégias de ensino, sugerindo tais relatos que os métodos adotados pelo docente podem, de alguma forma, influenciar o uso de estratégias por parte do aluno. Assim, a depender da escolha do professor, ele poderá atingir todos os tipos de alunos, como, por exemplo aqueles que têm maior facilidade em teoria ou como aqueles que preferem atividades mais práticas. 
Outros estudos também apontaram a influência do professor, tais como Monteiro et al. (2005) e Souza (2010), que indicaram o docente como sujeito que pode incentivar os discentes a refletirem e serem mais ativos no seu processo de aprendizado. Além disso, Silva e Biavatti (2018) sugeriram que a diversidade de métodos de ensino, aplicada pelo professor, pode colaborar na ampliação do uso de estratégias de aprendizagem autorreguladas pelos discentes.

\subsubsection{Análise dos Relatos}

Ainda observando os dados de análise qualitativa, conforme mencionado na metodologia, foi solicitado aos participantes, durante as oficinas realizadas nos dois semestres de 2019, que relatassem suas opiniões sobre as estratégias de aprendizagem adotadas no processo de aprendizagem até o momento em que eles participaram deste estudo e que consideram que os ajudam a enfrentar seus principais obstáculos de aprendizagem. Foi solicitada também a opinião deles sobre como os professores podem auxiliar na adoção das estratégias de aprendizagem no ambiente escolar.

Os relatos extraídos a partir das duas oficinas realizadas no primeiro semestre de 2019 são resultado da fala de 70 alunos, sendo 37 da turma A e 33 da turma B. Já nas outras duas oficinas, realizadas no segundo semestre de 2019, 66 alunos participaram, os quais divididos igualmente, sendo 33 da turma A e 33 da turma B. É importante frisar que todos os participantes concordaram com a utilização de suas respostas neste estudo.

Com o material extraído dos relatos, elaborou-se uma nuvem de palavras a fim de visualizar a frequência das palavras escritas pelos alunos. Essa nuvem de palavras (Figura 2) contém "adjetivos", "substantivos" e "verbos", as quais foram utilizadas como palavras-chave ativas.

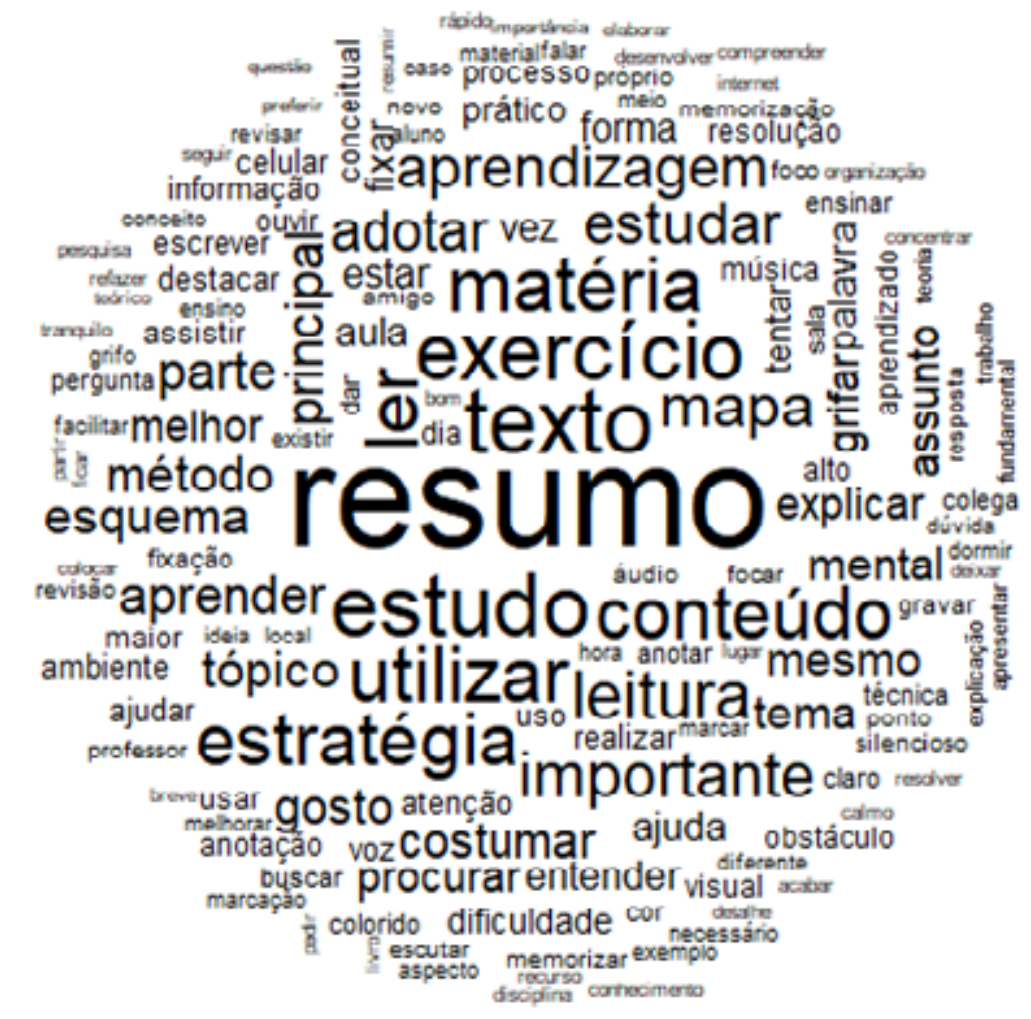

Figura 2. Nuvem de palavras dos relatos

Fonte: dados da pesquisa. 
A frequência geral identificou um total de 594 palavras ativas que foram escritas 2177 vezes pelos respondentes. De acordo com a nuvem (Figura 2), as palavras centralizadas, que se destacam pelo tamanho da fonte, são as mais utilizadas nas respostas durante os relatos. Percebe-se, nitidamente, que as palavras "resumo" (66 menções), "texto" (38 menções) e "estudo" (37 menções) foram as mais frequentes e representam, respectivamente, $3,03 \%, 1,75 \%$ e 1,70\% da frequência geral.

Para entender o sentido das palavras mais repetidas ("resumo", "texto" e "estudo"), realizou-se uma subanálise. Assim, foi possível notar que a frequente utilização da palavra "resumo" está ligada ao fato de os alunos adotarem bastante essa estratégia de aprendizagem, acreditando a maioria deles que, por meio de resumos e mapas mentais, há uma maior fixação e entendimento do conteúdo. Já a palavra "texto" reforça que uma boa forma para alcançar bons resultados no estudo também depende da leitura de textos e da extração de suas partes principais. Por fim, a palavra "estudo" emerge para intensificar todos os métodos adotados pelos alunos que refletem nos estudos de cada um.

Mediante os relatos descritos pelos alunos, destacam-se alguns trechos que se relacionam com as estratégias de aprendizagem e ensino.

No processo de aprendizagem, eu costumo usar o método de resumo, mas eu uso resumos rápidos divididos em tópicos com pouquíssimas anotações. Gosto de usar canetas coloridas e mudar o tamanho e formato da letra $[\ldots](\mathrm{B} 1 \mathrm{P} 3)$.

Geralmente, faço esquemas com partes que grifei do texto. Quando o conteúdo é mais complexo, busco assistir videoaulas. Resolver listas de exercício ou explicar para um colega o conteúdo me ajuda consolidar a aprendizagem (A1P9).

Leitura, procurando identificar palavras e sentenças-chave no texto. Depois, desenvolvo uma outra leitura, desta vez, elaborando perguntas com respostas. A seguir, tento explicar o que foi estudado para alguém (A1P35).

Para Castro et al. (2016), os discentes recorrem às estratégias de aprendizagem para obter o conhecimento de forma mais consistente. Conforme relatado, os alunos buscam meios com os quais mais se identificam para auxiliá-los no processo de aprendizagem, simplificando o conteúdo e facilitando o entendimento, a fim de promover resultados maiores e melhores, o que reforça os apontamentos de Souza (2010).

Observou-se também, pelos relatos, a percepção dos alunos quanto ao papel do professor na escolha das estratégias.

Adotar diferentes estratégias audiovisuais. Ouvir os alunos sobre as formas e melhores alternativas que cada aluno adota ao estudar (A1P36).

Os professores podem ser mais dinâmicos durante suas aulas, saindo da estrutura convencional e adotando medidas que estimulem a aula, como estudo de caso (ligar o conteúdo com realidade) (A1P31).

[...] ajudaria, explorando mais os exercícios relacionados à matéria, resolvê-los em sala com mais frequências (A1P25).

Uma das formas seria repassar ideias de estudos que obteve uma melhora no desempenho de algum aluno ou através de atividades que podem auxiliar em uma dificuldade que um aluno esteja apresentando (B2P9).

Ajuda individual na dificuldade de cada aluno, auxiliando a elaborar estratégias de melhor aprendizado (B2P6). 
Os docentes, de acordo com os relatos, devem estar sempre atualizados para ministrar suas aulas. Existem, hoje, inúmeros canais e tecnologias focadas no processo ensino-aprendizagem, o que gera maior interatividade entre aluno e professor. Entende-se que esses relatos, reforçam a importância da formação e atualização constante dos professores, para que possam acompanhar e auxiliar os discentes, não só nos conteúdos, como também nas formas de estudar.

Logo após as assertivas referentes às estratégias de aprendizagem, no final do questionário, os respondentes se deparavam com uma pergunta adicional que objetivou interrogá-los sobre as principais distrações que eles consideravam na hora de estudar, devendo os alunos responder à pergunta de forma escrita. Dentre as respostas mais recorrentes quanto às distrações que podem prejudicar os estudos, destacam-se o uso de internet, a redes sociais, o celular e os aparelhos eletrônicos em geral.

Ressalta-se ainda que, na escala das estratégias de aprendizagem utilizadas no questionário, também havia uma pergunta relacionada às distrações com o fim de identificar se os estudantes escutam música, assistem à televisão e/ou acessam a internet enquanto estudam ou fazem a tarefas de casa. Identificou-se que a média da nota atribuída pelos respondentes foi de 4,5 , considerando a nota máxima de 10 , sendo esse um valor considerado baixo diante da facilidade e disponibilidade, atualmente, de acesso à música, televisão e internet no cotidiano do indivíduo. Em contrapartida, alguns dos alunos respondentes atingiram a pontuação máxima (10), ou seja, esses são os alunos que acessam frequentemente os meios eletrônicos.

Ao considerar a resposta escrita de alguns alunos, observa-se que as redes sociais têm se tornado motivo de procrastinação. Mateus e Brito (2011) mostram que os discentes conectados à internet tendem a ficar dispersos durante as aulas, seja acessando redes sociais ou se comunicando com outros indivíduos em momentos inadequados. Com isso, não é de se impressionar quando pesquisas apontam que o celular é a maior distração existente na hora do estudo, ocupando lugar no ranking juntamente com as redes sociais e internet, os quais estão todos internamente ligados.

O excesso da virtualidade acomoda os indivíduos, fazendo com que eles posterguem seus estudos, o que pode influenciar no desempenho acadêmico dos discentes. Araújo, Santos e Alves (2019) mostram que o uso inadequado do celular durante as aulas e as atividades acadêmicas é um problema que está diretamente associado ao rendimento acadêmico dos discentes. A falta de foco, as companhias, os ruídos externos e o cansaço ainda causam distrações para uma parcela de estudantes, porém nem se comparam ao uso do celular.

Em suma, nota-se que os discentes recorrem a estratégias de aprendizagem para auxiliar nos estudos, seja por meio de anotações, leituras e resolução de exercícios. Além disso, o papel do docente é importante para o auxílio dos alunos no quesito referente ao aprimoramento da aprendizagem e do uso de estratégias. Entretanto, é necessário se atentar para as distrações que podem prejudicar os estudos, como, por exemplo, o uso do celular, que pode se tornar uma ferramenta que atrapalha o processo de aprendizagem ao invés de trazer contribuições.

\section{Considerações Finais}

O presente estudo propôs a verificar se ingressantes universitários do curso de Ciências Contábeis adotam estratégias de aprendizagem e qual a sua percepção sobre o papel do professor na escolha dessas estratégias. Para isso, foram analisadas quatro turmas de ingressantes de uma universidade pública, cujos estudantes responderam a um questionário que permitiu identificar o uso de estratégias de aprendizagem (cognitivas e metacognitivas), bem como a ausência de estratégias. Os discentes também entregaram relatos escritos e alguns participaram de grupos focais, respondendo a questões sobre o uso das estratégias. 
Em média, dos grupos de estratégias de aprendizagem analisados, percebe-se que os discentes utilizam, em maior número, as estratégias metacognitivas, que consistem em conhecer o próprio conhecer, ou seja, verificar como se aprende (Ribeiro, 2003). Assim, de modo geral, verificou-se que os discentes percebem e reconhecem a importância do processo de aprendizagem e que as estratégias de ensino são adotadas por muitos deles. Entretanto, nota-se que existe uma parcela que não adota qualquer estratégia que auxilie na aprendizagem, a respeito disso vale pontuar o relato de alguns discentes que declararam distrações associadas ao uso de celulares, internet, entre outras, que dificultam os estudos.

Ao considerar os discentes que fazem uso de estratégias, notou-se que eles recorrem a ferramentas como mapas mentais, revisão, resumos, compartilhamento de ideias, entre outras. Essas ferramentas fazem parte do processo de aprender e tem como objetivo prevenir as dificuldades de aprendizagem, como assinala Boruchovitch (1999). Além disso, foi possível perceber nesta pesquisa que o professor tem um papel importante nas escolhas das estratégias de aprendizagem, conforme pode ser visto no relato dos alunos que apontaram o docente como um indivíduo experiente com o conteúdo e que pode contribuir com o compartilhamento de técnicas para melhorar os estudos e o rendimento. Isso corrobora estudos anteriores (Ballantine, Duff \& Larres, 2008; Hall et al., 2004; Morozini et al., 2007; Oliveira et al., 2009; Silva \& Biavatti; 2018), que apontaram a influência dos professores no comportamento dos discentes.

Em relação aos docentes, torna-se evidente a relevância da diversificação das metodologias de ensino aplicadas em sala de aula. Este procedimento poderá contribuir para o processo de aprendizagem dos estudantes e, principalmente, atender aos diversos estilos de aprendizagem deles, estimulando também o uso de diferentes estratégias. Os docentes também podem atuar em conjunto com a coordenação do curso para que sejam promovidas atividades institucionais de intervenção com o objetivo específico de apresentar possíveis estratégias de aprendizagem.

O presente estudo contribui para o entendimento de como os ingressantes do curso de Ciências Contábeis reconhecem, adotam e colocam em prática as estratégias de aprendizagem. A partir dos achados encontrados, infere-se que a maior parte dos participantes já adotavam estratégias durante os estudos no ensino médio, julga-se que esse é um aspecto positivo, porém ressalta-se a importância do acompanhamento dos discentes ao longo da graduação, pois, conforme evidências anteriores (Silva \& Biavatti, 2018; Castro et al., 2016), há fatores como fase do curso e até motivação que podem afetar o uso dessas estratégias de aprendizagem.

Dessa forma, ainda que de modo geral os achados do presente estudo, com ingressantes, tenham sido similares aos resultados de estudos anteriores com graduandos, especialmente de contabilidade, é relevante pontuar que no ensino superior os estudantes se deparam com mais exigências, além de desafios pessoais, como o início da vida profissional. Nesse sentido, destaca-se que nos relatos dos ingressantes que o fato de estar trabalhando e estudando ao mesmo tempo pode afetar a escolha das estratégias de aprendizagem, entende-se que esse é um indicativo de que ao ingressar na vida universitária, os discentes necessitam se preparar para conciliar as diversas atividades com os estudos e reforça a importância de preparação dos docentes, para que eles possam auxiliar os estudantes a buscarem estratégias com o objetivo de terem melhor aproveitamento no aprendizado.

Quanto às delimitações, a pesquisa analisou os ingressantes do curso de Ciências Contábeis apenas de uma instituição; e quanto às limitações, destaca-se que a pesquisa foi realizada em um momento único, em uma instituição pública e a participação do grupo focal contou com menos participantes, já que a adesão foi voluntária. Dessa forma, sugere-se, em estudos futuros, estender a pesquisa a outras instituições de ensino, públicas e privadas, bem como verificar o motivo pelo qual os alunos não colocam em prática as estratégias de aprendizagem ou investigar a mesma população do presente estudo, porém ao final do curso, uma vez que o amadurecimento durante o curso, a interação discente-discente ou docente-discente, e/ou o ambiente podem ter impactado na adoção das estratégias. 


\section{Referências}

Abdullah, M. F. N. L., Ghani, S. A., Ahmad, C. N. C, \& Yahaya, A. (2015). Students' Discourse in Learning Mathematics with Self-Regulating Strategies. Procedia Social and Behavioral Sciences, 191, 2188-2194.

Araújo, M. A. S., Santos, B. B., \& Alves, M. H. (2019). O uso do telefone celular em sala de aula: percepção dos acadêmicos de Biologia, Campus Ministro Reis Velloso da UFPI (Brasil). Espacios, 40(17).

Ballantine, J. A., Duff, A., \&Larres, P. M. (2009). Accounting and business students' approaches to learning: a longitudinal study. Journal of Accounting Education, 26(4), 188-201. Doi: https://doi. org/10.1016/j.jaccedu.2009.03.001

Bardin. L. (1977). Análise de conteúdo. Lisboa: Editora Edições 70.

Borges, L. F. M. (2016). Estilos e estratégias de aprendizagem: um estudo com discentes do curso de Ciências Contábeis. Dissertação de mestrado, Universidade Federal de Uberlândia, Uberlândia, MG, Brasil. Doi: http://doi.org/10.14393/ufu.di.2016.568

Boruchovitch, E. (1994). As variáveis psicológicas e o processo de aprendizagem: Uma contribuição. Psicologia: Teoria e Pesquisa, 10(1), 129-139.

Boruchovitch, E. (1999). Estratégias de aprendizagem e desempenho escolar: considerações para a prática educacional. Psicologia: Reflexão e Crítica, 12(2). Doi:10.1590/S0102-79721999000200008

Boruchovitch, E., \& Santos, A. A. A. dos. (2015). PsychometricStudies of the Learning Strategies Scale for University Students. Paideia (Ribeirão Preto), 25(60), 19-27. Doi https://doi.org/10.1590/198243272560201504

Boruchovitch, E., Santos, A. A. A., Costa, E. R., Neves, E. R. C., Primi, R., \& Guimarães, S. E. R. (2006). A construção de uma escala de estratégias de aprendizagem para alunos do ensino fundamental. Psicologia: Teoria e Pesquisa, 22(3), 297-304. Doi: https://doi.org/10.1590/S010237722006000300006

Caplan, S. (1990). Using focus group methodology for ergonomic design. Ergonomics, 33(5), 527-33. Doi:10.1080/00140139008927160

Casanova, A. M.A., Aráujo, A. M.\& Almeida, L.S. (2020). Dificuldades na adaptação académica dos estudantes do $1^{\circ}$ ano do Ensino Superior. Revista E-Psi, 9 (1), 165-181.

Castro, J. X., Miranda, G. J., \& Leal, E. A. (2016). Estratégias de Aprendizagem dos estudantes motivados. Advances in Scientific and Applied Accounting, 9(1), 80-97. Recuperado em 1/12/2021 de https:// asaa.anpcont.org.br/index.php/asaa/article/view/258

Cervo, A. L., \& Bervian, P. A. (1996). Metodologia científica (4a ed.). São Paulo: Makron.

Corso, H. V., Sperb, T. M., Jou, G. I. D., \& Salles, J. F. (2013). Metacognição e funções executivas: relações entre os conceitos e implicações para a aprendizagem. Psicologia: teoria e pesquisa, 29(1), 21-29. Recuperado em 1/12/2021 de https://periodicos.unb.br/index.php/revistaptp/article/view/17593

Daciê, F. do P. \& Anzilago, M. (2019). Efeito da Motivação dos Acadêmicos de Ciências Contábeis sobre As Estratégias de Aprendizagem Adotadas por Eles: estudar ou compreender? Revista Mineira de Contabilidade, 20(3), 90-104.Doi: https://doi.org/10.21714/2446-9114RMC2019v20n3t07 
Dembo, M. H. (1994). Applying educational psychology (5th ed.). New York: Longman Publishing Group.

Flavell, J. H. (1979). Metacognition and cognitive monitoring: a new area of cognitive-developmental inquiry. American psychologist, 34(10), 906. Doi: https://doi.org/10.1037/0003-066X.34.10.906

Freire, L. G. L. (2009). Auto-regulação da aprendizagem. Ciências \& Cognição, 14(2), 276-286. Recuperado em 1/12/2021 de http://www.cienciasecognicao.org/revista/index.php/cec/article/view/115

García-Pérez, D., Fraile, J., \& Panadero, E. (2020). Learning strategies and self-regulation in context: How higher education students approach different courses, assessments, and challenges. European Journal of Psychology of Education, 36(2), 533-550. Doi: https://doi.org/10.1007/s10212-020-00488-z

Glogger, I., Schwonke, R., Nuckles, M.; Renkl, A.; Holzäpfel, L. (2012). Learning Strategies Assessed by Journal Writing: Prediction of Learning Outcomes by Quantity, Quality, and Combinations of Learning Strategies. Journal of Educational Psychology, 104(2), 452-468. Doi: 10.1037/a0026683

Hall, M., Ramsay, A., \& Raven, J. (2004). Changing the learning environment to promote deep learning approaches in first-year accounting students. Accounting Education: an International Journal, 13(4), 489-505. Doi:10.1080/0963928042000306837

Lima Filho, R. N., Lima, G. A. S. F. D., \& Bruni, A. L. (2015). Aprendizagem Autorregulada em Contabilidade: Diagnósticos, Dimensões e Explicações. Brazilian Business Review, 12(1), 38-56.

Mateus, M. C., \& Brito, G. S. (2011). Celulares, smartphones e tablets na sala de aula: complicações ou contribuições. Artigo apresentado no $10^{\circ}$ Congresso Nacional em Educação (EDUCERE), Curitiba, PR.

Mayer, R. E. (1988). Learning strategies: An overview. Learning and study strategies, 11-22. Doi:10.1016/ B978-0-12-742460-6.50008-6

Monteiro, S., Vasconcelos, R., \& Almeida, L. S. (2005). Rendimento acadêmico: influência dos métodos de estudo. Artigo apresentado no $8^{\circ}$ Congresso Galaico-Português de Psicopedagogia, Braga, Portugal.

Morozini, J. F., Cambruzzi, D., \& Longo, L. (2007). Fatores que influenciam o processo de ensino aprendizagem no curso de ciências contábeis do ponto de vista acadêmico. Capital Científico, 5(1).

Oliveira, K. L. D., Boruchovitch, E., \& Santos, A. A. A. D. (2010). Estratégias de Aprendizagem e Desempenho Acadêmico: Evidências de Validade. Psicologia: Teoria e Pesquisa, 25(4), 531-536. Recuperado em 1/12/2021 de https://periodicos.unb.br/index.php/revistaptp/article/view/17415

Panadero, E., \& Alonso Tapia, J. (2014). How do Students Self-Regulate? Review of Zimmerman's Cyclical Model of Self-Regulated Learning. Anales de psicologia, 30(2), 450-462.

Ribeiro, C. (2003). Metacognição: Um Apoio ao Processo de Aprendizagem. Psicologia: Reflexão e Crítica, 16(1), 109-116. Doi: 10.1590/S0102-79722003000100011

Simão, A. M. da V., \& Frison, L. M. B. (2013). Autorregulação da aprendizagem: abordagens teóricas e desafios para as práticas em contextos educativos. Cadernos de Educação, (45), 02-20.

Silva, T. B. de J. \& Biavatti, V. T. (2018). Estratégia metacognitiva de aprendizagem autorregulada, percepção docente sobre a aprendizagem e métodos educacionais em contabilidade. Revista Contemporânea de Contabilidade, 15(37), 3-33. Doi: https://doi.org/10.5007/2175-8069.2018v15n37p3

Souza, L. F. N. I. D. (2010). Estratégias de aprendizagem e fatores motivacionais relacionados. Educar, 26(36), 95-107. Recuperado em 1/12/2021 de https://revistas.ufpr.br/educar/article/view/17583/11521 
Valle Arias, A., Lozano, A. B., \& Cabanach, R. G. (1999). Las estrategias de aprendizaje revisión teórica y conceptual. Revista Latinoamericana de Psicología, 31(3), 425-461.

Vasconcelos, Y. L., \& Araújo, R. H. M. D. (2017). Emprego da técnica de mapas conceituais em disciplinas de contabilidade com abordagem gerencial. Ambiente Contábil, 9(1), 117-143. Doi: https://doi. org/10.21680/2176-9036.2017v9n1ID8889

Vaughn, S., Schumm, J. S., \& Sinagub, J. (1996). Focus group interviews in education and psychology. Thousand Oaks, CA: SagePublications.

Warr, P, \& Downing, J. (2000). Learning strategies, learning anxiety and knowledge acquisition. British Journal of Psychology, 91(3), 311-333. Doi: https://doi.org/10.1348/000712600161853

Waterkemper, R., \& do Prado, M. L. (2011). Estratégias de ensino-aprendizagem em cursos de graduação em Enfermagem. Avances en Enfermería, 29(2), 234-246. Recuperado em 2/12/2021 de https:// revistas.unal.edu.co/index.php/avenferm/article/view/35793

Weinstein, C. E., Acee, T. W., \& Jung, J. (2011). Self regulation and learning strategies. New Directions for Teaching and Learning, 16. Doi: https://doi.org/10.1002/tl.443 